\title{
Reproducing the Management Process in an Educational Context
}

\author{
Alastair Nicholson \\ London Business School
}

E-mail:upenney@lbs.ac.uk

Key words: interactive learning, management education, group interaction

Abstract: $\quad$ New learning methods have a major part to play in management education. Traditional learning methods can be used effectively on subjects such as finance, economics and some aspects of human resource management which are based on a body of knowledge. But the subject of operations and production management which requires managers to manage the situation needs new approaches to education. This article defines the requirements for the reproducing of the managerial challenges as they really are, and it proposes a scheme providing a laboratory for management learning. The scheme has been tested exhaustively and the article reports on the outcome of these learning experiments across a comprehensive set of managerial issues.

\section{THE PROBLEM OF REPRODUCING THE TASK OF MANAGEMENT}

Few commentators would credit Business Schools or Schools of Management with having solved the problems of management. The language of Business can be learnt and the issues raised and discussed but the process of management itself remains firmly inside the workplace. Management education is usually presented through the traditional media of lectures, case studies and discussions in the safety of the classroom well away from the real time pressures and priorities which managers actually 
face. Even the most modern textbooks can only refer to topics not management itself (1). Attempts are made to bridge this gap through simulations, games, exercises, plant tours and by introducing visiting speakers from business to report their practical experiences. Realistic games are becoming more common in Europe for illustrating the challenges of organisation, but these often have a specific focus in mind such as demonstrating Just-in-Time concepts rather than exposing the confrontation of open-ended issues which managers face.

The challenge to be addressed is how to recreate the managerial context within a classroom setting given the variety of management situations and the constraints of the educational process. This issue has persisted within our own institution at the London Business School for many years. Eight years ago we started to use videos taken inside companies of managers and place these within the context of case studies to demonstrate the manager in action. We also developed courses which involved students in small groups working on managerial projects. Both these schemes contributed to the learning of the reality of management but the students could not feel the pressures of practice (2). More recently our principal aim has been to create a realist management laboratory through which we could re-produce the managerial experiments which actually take place. The test was how to recreate the realism, the experimentation and combine these aspects with the efficiency, flexibility and disciplines required in the classroom which are essentially contradictory. Nevertheless over the last five years a managerial test environment has been created which we believe fulfils these conditions successfully.

The development of the managerial learning experience has been the product of a number of inputs:

- a long series of experiences with managers who have to cope concurrently with technical, logistical, human and commercial issues which has been drawn upon in developing the exercise

- the recognition that a classroom of students could be formulated into a set of managerial problems where "the organising of the people" is the central issue

- the availability of interactive inexpensive communication technology which could both discipline the exercises as well as reproduce the role of IT and provide the data needed for analysis

Our aim was to reproduce the situation in which the students could live their own case study. The following sections define the properties of the management learning laboratory and the series of concepts and learning stages which it provides. 


\section{THE REQUIREMENTS OF THE MANAGEMENT SYSTEM}

Various production games have been developed in the form of physical exercises in which a small physical object is produced. Games have also been developed in the form of in the form of computer based simulations. Some computer-based simulations are intended to illustrate the complexity of decision making for scheduling, for demonstrating MRP etc. Other classic business simulations are used to demonstrate and explore competitive behaviour - the most well known being the game Markstrat.

Few of the existing games demonstrate the management problems of organisational design, process improvement and negotiation, and the linking of operational actions with commercial outcomes. To recreate those managerial processes it is crucial to focus on the managerial challenge even more than the technical or computational challenges. The way in which the required business environment has been achieved has been to include certain key ingredients:

- the definition of a business context in terms of negotiable contracts with external stakeholders

- the necessity to physically 'manufacture' an object which has potential quality problems with prices, costs etc

- the provision of an automatic IT scheme and public display system through which the pressures and the accountability are imposed without requiring pressure from the tutor who can in effect remain as a referee of success

- the idea of progressing towards a desired end result with no predefined pathway to the end, thus recognising the process of business advance as a series of experiments on the operational situation.

Developing this type of situation implies complexity of educational approach where we are looking for simplicity of execution. This is the fundamental compromise in games exercises in production and operations management: how to retain the complexity of the real situation whilst providing the necessary simplicity and boundaries for tutor and students.

Over extensive trials we believe we have identified appropriate boundaries in the series of exercises which we have named Discovery. The learning of 'what to do' for the students in each exercise is guided by a short preliminary case study reading which introduces the situation, a short presentation on the structuring of a business operations in general and the illustration of that general structure on the features of the particular exercise. The specification of each exercise is thus positioned within the reality of a business setting. 
Secondly the timing and pacing are provided by a public display system from a PC projector which itself is linked through to a multiplexer to a set of small telepads which can communicate to the PC in order. This communication system can present status and records performance. The magic of this electronic recording is its immediacy, its imposition of pressure, its ability to enable analysis to be done from the data collected which is independent of verdicts passed by the tutor or students.

The third condition which leads to success is the staged development of the exercise which provides pathways through the experiments to build up the layers of learning. This pathway ensures that the learning takes place and that serious and significant questions can be asked as student assessment issues on completion of the exercise.

\section{THE DISCOVERY EXERCISE}

The series of exercises and experiences which have been developed have been branded under the name 'Discovery' and in its present form the scheme consists of two broad phases of learning each with subsections. They are constructed around the growth and expansion of a notional electronics company.

\section{Discovery I: Learning phases}

i) the recognition of the challenges of designing an operational system within a business environment

ii) the testing of that design by running orders through the system and engaging 'employees' within operational functions

iii) the evaluation mechanism

iv) the emergence of a series of improvement experiments to be tested as changes to the design to both remove problems and exploit market and supplier opportunities

v) the development of the commercial-operations relationship

vi) the recognition of the limits to potential performance in an operation

\section{Discovery II: Learning phases}

i) the ideas of structure in relation to strategy or systems

ii) the role of integrating and simplifying structure and mechanisms in the operations

iii) the organisation of the transition from one configuration to the next 
iv) the changed role of management as managing a model of the situation rather than the situation itself

v) the recognition of the changed potential for new product and process development within the new structure

Thus the total Discovery exercise has become capable of reproducing a whole series of learning exercises. The details of the exercise are shown in the diagrams attached:

- figure 1 shows the layout and logistical configuration of the Discovery system in which the 'stages' are set out for the production of the product

- figure 2 shows the display which indicates the current status or model for the manager of 'what is happening'

- figure 3 shows the instructors toolkit for presenting the series of exercises

- figure 4 shows the emerging themes for the various parties in the learning exercise

A unifying theme to the whole of the Discovery I exercise is the reference to operational design within a business context. The business context is presented as the fundamental constraints within which the operation must work - constraints which can be re-negotiated but normally at extra cost and which in turn makes more demand on the internal improvements.

The internal organisation is presented in terms of six subsystems which can be divided into three groups:

- technical

- operational

- appraisal the technical capability subsystem

the logistical layout subsystem

the order progressing subsystem the task allocation subsystem

the accounting and approval subsystem

the review and improvement subsystem

The series of initiatives within the Discovery exercise are continuously referred back to this unifying framework. It is that framework which provides students with a means of re-interpreting practices which they see in companies and as a medium through which improvements can be considered. 


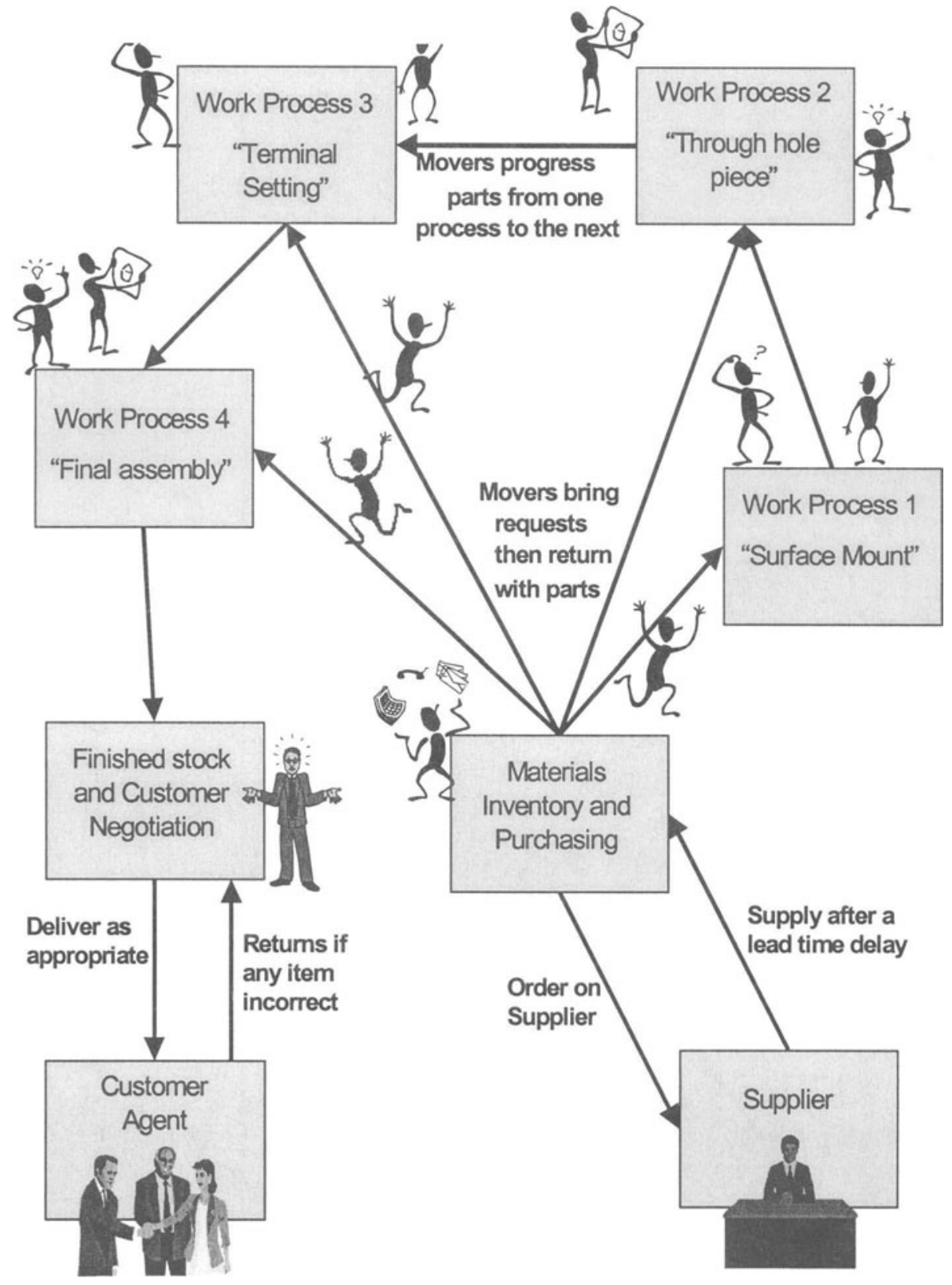

Figure 1 The Basic Operational configuration. Students occupy defined roles in the overall business operation for the running phase of the Discovery Participator. 


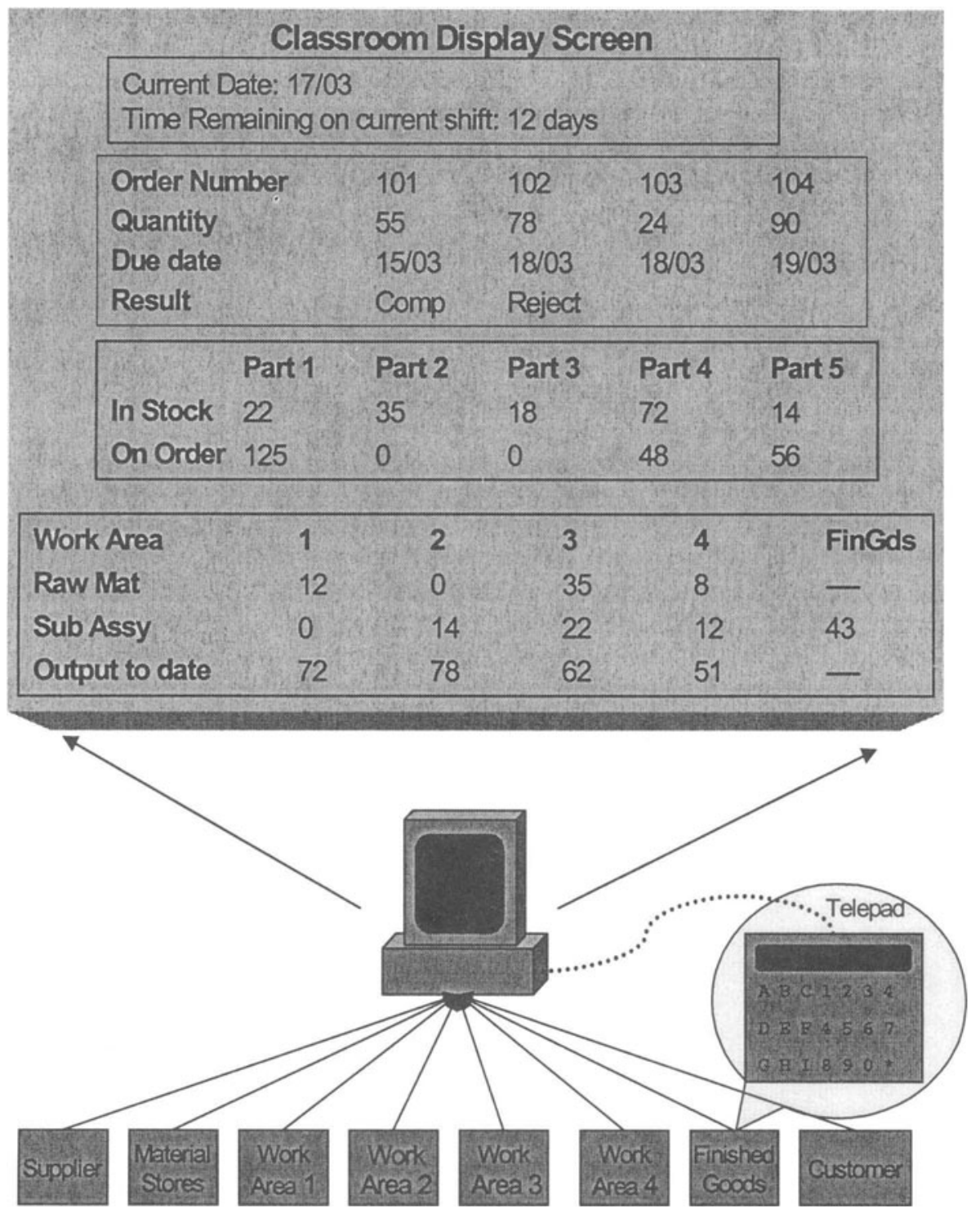

Figure 2. During the Run. The live display screen showing what is happening continously. Each area has a telepad to record the activity as it happens. 


\section{Student pre-reading material}

- The Discovery I case study: describes a new business start up and includes all necessary drawings and specifications with example outcomes of the first three months' progress of the company.

- The Discovery II case study: describes the proposed implementation of MRP, JT and cellular technologies for re-structuring the Discovery I business.

- Each student is given a role within the Discovery Exercise, an outline of the business plan and the design of the operation.

\section{Class set-up Materials}

- The Discovery 5 different component parts (Sticklebacks) for 'manufacturing' the product (100 pieces of each part plus a set of trays)

- 10 telepads linked to a multiplexer and to a PC and thus to a projector to an overhead (or a set of TVs) [Can use function buttons on PC as back up]

- A class room which is arranged as a mini-organisation of 8 working areas

- The guideline instructions for the instructor with a step by step action. All other instructions are embedded within the PC display

\section{Running the Discovery I Participator (2.5 hours)}

- Explaining the system and run

- Doing the first run and review 30 mins

- Explaining the IT system 30 mins

- Running with the full IT system and running results 30 mins

- Developing future improvements 30 mins

- Reviewing and assessing the process improvement

\section{Running the Discovery II Participator (2.5 hours)}

- Considering systems on operational technologies $30 \mathrm{mins}$

- Proposing, trying out and explaining MRP 30 mins

- Proposing, trying out and explaining JIT 30 mins

- Proposing, trying out and explaining Cellular format 30 mins

- Reviewing the internal and external potential and $30 \mathrm{mins}$ difficulties of adopting the three systems

Figure 3. Instructors Toolkit for the Discovery Participator 
In practical terms the Discovery Exercise combines several concurrent themes which provide the basis for the increasing sophistication of the exercise.

1. Practical stages of the experience consist of:

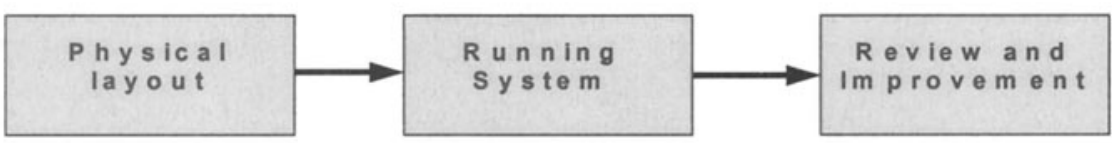

2. As achievement for the manager (represented by the instructor) and management

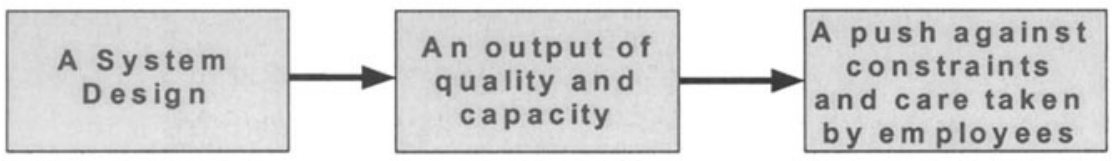

3. Guiding, controlling and motivating the activity and discussions is the real time information system which:

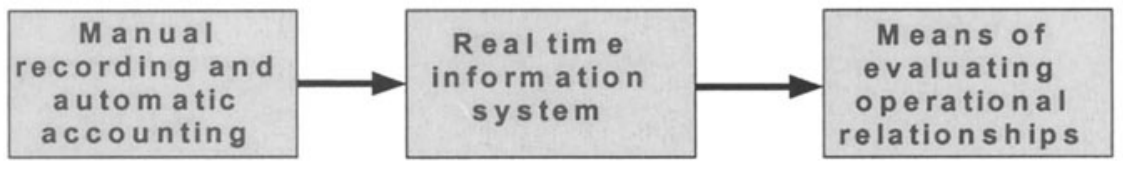

4. As a learning experience the student, both individually and as part of a team, progresses through a series of barriers:

\begin{tabular}{|c|c|c|}
\hline $\begin{array}{c}\text { The problem } \\
\text { of making } \\
\text { som ething } \\
\text { individually }\end{array}$ & $\begin{array}{c}\text { The task of } \\
\text { collective } \\
\text { organisation }\end{array}$ & $\begin{array}{c}\text { The pursuit of } \\
\text { profitability to } \\
\text { the physical } \\
\text { lim it }\end{array}$ \\
\hline
\end{tabular}

Figure 4. Organisation of the Learning 


\section{DEVELOPING THE IDEA OF RE- STRUCTURING THROUGH THE DIARY SYSTEM}

The Discovery I exercise aims to create the idea of organisation, evaluation and improvement and the art of experimentation as the basis of operational investment. But, realistically, like all enterprises the effort of continuous improvement reaches its limits. Seldom are there technical limits. The limits are managerial:

- the limits to maintaining the development of ideas

- the limits to continuing performance gains

- the feeling that the variability and slack which remains will just have to be coped with at the time and on the move

These limits are reached within four or five cycles of the improvement process.

At this stage the intention is to open up the idea of structural changes rather than continuous improvement changes. Structural changes mean that a new concept is introduced, radical alterations are made to the productprocess configuration to the roles and responsibilities. The need for such a change is normally prompted by new business pressures or the opportunities provided by new technology.

In the Discovery II exercise the proposal is to consider the impact of Justin-Time, Enterprise Resource Placing (as a development of MRP) and Cellular Organisation. Part of the learning objective is to see what these schemes mean as an implementation on an existing organisation. These concepts can be demonstrated or can be run as a full learning exercise. The richness of the learning here is that:

- The students are learning what the ideas mean as proposals to themselves on their own organisation, ie they have to face the ideas as existing owners of a working practice and thus have in their own minds the resistance to change (3).

- The ideas are all equal candidates for structural change. There is no need to assume that one system is better than another. Often games are developed to prove the JIT advantages

- Structural change must consider implications of control, information requirements, people implications as well as the potential to cope with a changing business environment

The exercise with Discovery II is therefore set out as the challenge of implementation of new systems or existing systems with an eye on organising technology as an investment which can be as rich or richer than 'technical' technology. The ideas are posed in terms of their classic concepts 
which are already well understood from textbooks and other readings. The questions for the exercise are then to pose the investment questions:

- which investment will relate to external gains of growth, diversification and product development?

- which investment will formulate the transition from what exists now most easily?

- which investment will require most change to the information and control system?

From the business point of view the most critical dilemmas are:

- what are the predicted gains in productivity from each investment and which costs will be most reduced?

- what will the new system offer in terms of managerial significance?

For each re-structuring the students are asked to act as proposers and resisters of the new scheme and as advocates and negotiators of the changes. The focal point of the discussion however is the recognition of the changing role of management for the new circumstances which the restructuring will lead to. Each of the schemes is used to identify a unique organising technology

- the process of information and planning is MRP

- the identification over any form of waste in JIT

- the potential for improvement in Cellular Organisation

Learning the value of these themes is only fundamentally achieved by students when they can recognise its potential and its risks in practice.

\section{EVIDENCE OF RESULTS}

The Discovery Exercise has now been worked numerous times with many audiences. It has been proved in various company learning situations and with numerous academic audiences. Beyond its strength in its the role as a learning tool, it has proved remarkably flexible in scope both for varying the length of the educational experience and in handling different numbers of students or participants who can be accommodated within the system. The Discovery experience can be run in a demonstration mode or in a brief running mode over a two-your session. Alternatively it can be worked over a full week in which the total operational learning can be explained with itemised learning points which can be applied to the business from which the participants come. It has been used with as few as nine students and as many as forty-five in a single run.

The distinctive learning points of the Discovery system include:

- the design of the working organisation 
- the evaluation of a working system

- the local improvement process

- the relationship of an operational system to its commercial results

- the recognition of a technology within an organisation

- the role of implementation of modern practices such as JIT, MRP and Cellular organisation

- the reviewing of structural change in terms of the simplicity of transition to new working arrangements

The most promising results of the scheme is the chance it has provided to reverse some established patterns in management education. Management education in Business Schools has retreated into teaching the external environment of business - finance, strategy, marketing, organisational culture. Whilst engineering related courses have still wanted answers to the problems of management. Until we are able to reproduce the 'situation' to be managed in the classroom, students of management will not be able to comprehend and enjoy taking on the challenges (4). The experience with the Discovery system has shown how it:

- develops a practice of management and thus reveal the ideas

- demonstrates the multiple inputs to the management process and the role of negotiation in deciding a next step

- displays that the variety of models produced by opinion, custom and practice, data, and design of the system as contributors to both change and resistance to change

- shows the reality of what IT systems can do

We are thus able to show the value of experience and established practice as the factors to be learnt and considered in the development of business education systems.

\section{REFERENCES}

von Hippel E. and M J Tyre (1995) How learning by doing is done: problem identification in novel process equipment Research Policy 24 pl-12

Schmenner R.W. (1986) Plant Tours in Production Management Science Research Associates Slack N. et al. (1998) Operations Management Pitman

Goffee R. and J Hunt (1997) The end of management? Classroom versus boardroom Financial Times, Mastering Management p631-635. 


\section{BIOGRAPHY}

\section{Alastair Nicholson}

Professor T. Alastair J. Nicholson has been at London Business School since 1970. His research theme is how the management processes in companies link the daily working practices to the business objectives. $\mathrm{He}$ also has a keen interest in how new teaching technologies can bring business reality to the classroom. 